\section{PC-002 PRELIMINARY RESULTS ON THE USE OF ORAL REHYDRATION SOLUTION IN THE FORM OF GELATO FOR REHYDRATION OF CHILDREN WITH ACUTE GASTROENTERITIS}

${ }^{1} \mathrm{G}$ Zvigule Neidere*, ${ }^{2} \mathrm{~A}$ Barzdina, ${ }^{3} \mathrm{G}$ Laizane, ${ }^{4}$ I Sviestina, ${ }^{5} \mathrm{~K}$ Gross. ${ }^{1}$ Riga Stradin University, Paediatrics, Riga, Latvia; ${ }^{2}$ Riga Stradins University, Anaesthesiology and Intensive Care, Riga, Latvia; ${ }^{3}$ Children's Clinical University Hospital, Infectology, Riga, Latvia; ${ }^{4}$ Children's Clinical University Hospital, Pharmacy, Riga, Latvia; ${ }^{5}$ Riga Technical University, Faculty of Materials Science and Applied Chemistry, Riga, Latvia

\subsection{6/ejhpharm-2019-eahpconf.83}

Background Oral rehydration solution (ORS) is used to reverse dehydration. Successful dehydration treatment replenishes lost water and electrolytes. It can be done by consuming ORS, containing both electrolytes and glucose, because sodium and glucose transport in the small intestine are coupled. However, clinical practice shows that children refuse ORS due to its salty-sweet taste and unpalatability.

Purpose We hypothesised that freezing ORS containing a fruit/ berry juice to a likeable texture in 'gelato' form could promote oral rehydration. This form has not previously been trialled for rehydration fluid administration.

Material and methods Apple and strawberry juice were the base and crystalline $\mathrm{NaCl}$, water and glucose were added to the concentrations recommended by the World Health Organisation (WHO) ORS standard and revised formulas. The WHO's standard formula contains $90 \mathrm{mmol} / \mathrm{L} \mathrm{Na}^{+}, 20 \mathrm{mmol} / \mathrm{L} \mathrm{K}^{+}, 80 \mathrm{mmol} / \mathrm{L} \mathrm{Cl}^{-}$and glucose $111 \mathrm{mmol} / \mathrm{L}$, but the WHO's revised formula contains $70 \mathrm{mmol} / \mathrm{L} \mathrm{Na}{ }^{+}, 20 \mathrm{mmol} / \mathrm{L} \mathrm{K}^{+}, 60 \mathrm{mmol} / \mathrm{L} \mathrm{Cl} ~^{-}$and glucose $75 \mathrm{mmol} / \mathrm{L}$. All ingredients were pasteurised at $80^{\circ} \mathrm{C}$ and cooled to $4^{\circ} \mathrm{C}$ in a shock freezer. The gelato was made in a Maestro HE. It was kept at $-20^{\circ} \mathrm{C}$ in a gelato coolbox and served at $-12^{\circ} \mathrm{C}$. Portions of $200 \mathrm{~g}$ were given to children at the Infection and Emergency Units. The Ethical Committee's approval was obtained. All parents gave informed consent for participation.

Results Thirty-six children (1-15 years' old) were enrolled in the study. Fourteen (39\%) children did not tolerate any amount, while $22(61 \%)$ ate ORS gelato. Seven patients (19.4\%) ate $\geq 10 \mathrm{~g} / \mathrm{kg} / \mathrm{h}$ (ORS consumption rate needed for acute dehydration phase). The mean amount eaten was $4.6 \mathrm{~g}$ per weight $\mathrm{kg}$ (SD $5.78 \mathrm{~g} / \mathrm{kg}$ ) - the rate needed for the maintenance of rehydration. There is a statistically significant correlation with the willingness to eat the gelato and a reported likeness of taste (Spearman rho value 0.639, p<0.001).

Conclusion Our results show that ORS can be successfully administered frozen as gelato. The small sample size is the major limitation of this study. Additional research is needed before we can introduce ORS gelato into clinical practice.

\section{REFERENCES AND/OR ACKNOWLEDGEMENTS}

The team acknowledges Ice Bliss SIA for making the gelato.

No conflict of interest.

\section{PC-003 WEIGHT-LOWERING PSEUDOEPHEDRINE-BASED PRESCRIPTIONS: MONITORING PATIENT FEEDBACK AFTER UPDATE OF NATIONAL PRICE LIST OF MEDICINES AND MAGISTRAL PREPARATION}

\footnotetext{
${ }^{1} \mathrm{~A}$ Pirrone* ${ }^{2}{ }^{2} \mathrm{~V}$ Marangon, ${ }^{2} \mathrm{AA}$ Nisic, ${ }^{2} \mathrm{~F}$ Panzeri, ${ }^{1} \mathrm{~L}$ Cavallo, ${ }^{2} \mathrm{AL}$ Manfredi, ${ }^{2} \mathrm{G}$ Palmieri, ${ }^{2}$ MG Pizzonia, ${ }^{2} \mathrm{M}$ Avantaggiato. ' Universita Degli Studi di Milano, Scienze Farmaceutiche Scuola di Specializzazione in Farmacia Ospedaliera, Milano, Italy; ${ }^{2}$ ATS Brianza, Pharmacy Service, Monza, Italy
}

10.1136/ejhpharm-2019-eahpconf.84
Background The decree 27/07/2017 of the Ministry of Health allow the prescription and dispensation in private pharmacies of weight-lowering magistral preparations containing pseudoephedrine. The commercially available pharmaceutical equivalent is unsuitable. Meanwhile, on 9 November 2017, the National Price List of Medicines and Magistral Preparation (NPM) was updated. Among several changes introduced, the price of magistral preparations were increased by $40 \%$ in order to offset additional charges related to general, preliminary and subsequent professional activities linked to preparation and dispensation. The hospital pharmacist, operating in the local pharmaceutical services, guarantees the appropriate supervision of these prescriptions.

Purpose To evaluate whether the price change, due to update of the NPM, has affected the number of prescriptions and patients considering a territorial pharmaceutical service.

Material and methods The number of prescriptions, patients and price of preparations, and other data regarding prescriptions have been collected using Microsoft Excel. Period analysis according to date of dispensation: from 1 September 2017 to 11 August 2018, divided into five 69 day periods (from P1 to P5), of which one was prior and four after 9 November 2017.

Results In the analysed period, from 1 September 2017 to 11 August 2018, 1671 prescriptions were dispensed, referring to 442 patients from 17 different pharmacies. The average number of patients treated per period was 159. P1: 236 preparations, 158 patients, average price $€ 16.79$. P2: 321 preparations, 170 patients, average price $€ 30.35 . \quad$ P3: 310 preparations, 148 patients, average price $€ 31.52$. P4: 343 preparations, 147 patients, average price $€ 31.98$. P5: 461 preparations, 184 patients, average price $€ 31.63$.

Conclusion The average price between the first and fifth period has increased by $88 \%$. Despite the substantial increase in price, there has not been a substantial variation in the number of dispensations and patients treated, underlining that the pharmacist's professionalism and his galenic skills can compensate for the lack of suitable commercially available pharmaceutical equivalents.

\section{REFERENCES AND/OR ACKNOWLEDGEMENTS}

Law 94/1998, Decree 27/07/2017 of the Ministry of Health, Decree 22/09/2017 of the Ministry of Health.

No conflict of interest.

\section{PC-004 WHAT HAPPENS WHEN INSULIN ASPART IS DILUTED IN DEXTROSE?}

${ }^{1} \mathrm{LH}$ Préta*${ }^{2} \mathrm{H}$ Henry, ${ }^{2} \mathrm{M}$ Masse, ${ }^{1} \mathrm{~N}$ Carta, ${ }^{1} \mathrm{M}$ Kouach, ${ }^{1} \mathrm{C}$ Foulon, ${ }^{1} \mathrm{JF}$ Goossens, ${ }^{2} \mathrm{D}$ Lannoy, ${ }^{2} \mathrm{~S}$ Genay, ${ }^{2} \mathrm{~B}$ Decaudin, ${ }^{2} \mathrm{P}$ Odou. ${ }^{1}$ Université de Lille, EA 7365 - Grita Groupe de Recherche sur les Formes Injectables et les Technologies Associées, Lille, France; ${ }^{2}$ Université de Lille- Chu de Lille, EA 7365 - Grita - Groupe de Recherche sur les Formes Injectables et les Technologies Associées, Lille, France

\subsection{6/ejhpharm-2019-eahpconf.85}

Background In hospital, medications for infusion are mostly diluted in saline. In neonatal resuscitation, glycaemic instabilities are frequently observed in premature newborns, hence insulin treatment is started. In our establishment, insulin aspart is used and diluted in a 5\% dextrose solution (D5\%), due to sodium restrictions in newborns.

Purpose To evaluate the impact of the choice of D5\% diluent on the stability of the insulin aspart at $1 \mathrm{U} / \mathrm{mL}$. 